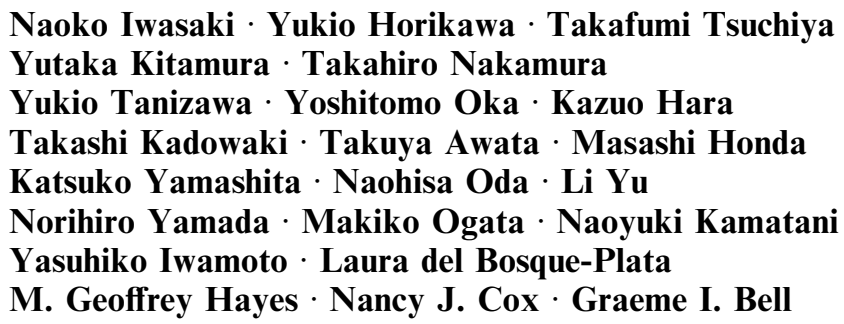

\title{
Genetic variants in the calpain-10 gene and the development of type 2 diabetes in the Japanese population
}

Received: 14 September 2004/ Accepted: 10 December 2004/Published online: 5 February 2005

(C) The Japan Society of Human Genetics and Springer-Verlag 2005

Abstract Variation in the gene encoding the cysteine protease calpain-10 has been linked and associated with risk of type 2 diabetes. We have examined the effect of three polymorphisms in the calpain-10 gene (SNP-43, Indel-19, and SNP-63) on the development of type 2 diabetes in the Japanese population in a pooled analysis of 927 patients and 929 controls. We observed that SNP-43, Indel-19, and SNP-63 either individually or as a haplotype were not associated with altered risk of type 2 diabetes with the exception of the rare 111/ 221 haplogenotype (odds ratio $(\mathrm{OR})=3.53, P=0.02$ ). However, stratification based on the median age-

Naoko Iwasaki, Yukio Horikawa and Takafumi Tsuchiya contributed equally to this work.

N. Iwasaki $(\bowtie) \cdot M$. Ogata $\cdot$ Y. Iwamoto

Diabetes Center, Tokyo Women's Medical University,

8-1 Kawada-cho, Shinjuku-ku,

Tokyo 162-8666, Japan

E-mail: niwasaki@dmc.twmu.ac.jp

Tel.: + 81-3-33538111

Fax: + 81-3-33581941

Y. Horikawa $\cdot$ L. Yu $\cdot$ N. Yamada Laboratory of Molecular Genetics,

Department of Cell Biology,

Institute for Molecular and Cellular Regulation,

Gunma University, Maebashi, Japan

T. Tsuchiya $\cdot$ L. del Bosque-Plata · M. G. Hayes · N. J. Cox ·

G. I. Bell

Departments of Biochemistry and Molecular Biology,

Human Genetics and Medicine,

The University of Chicago,

Chicago, Illinois, USA

Y. Kitamura · T. Nakamura $\cdot$ N. Kamatani

Department of Statistical Genetics,

Institute of Rheumatology,

Tokyo Women's Medical University,

Tokyo, Japan at-diagnosis in the pooled study population $(<50$ and $\geq 50$ years) revealed that allele 2 of Indel- 19 and the 121 haplotype were associated with reduced risk in patients with later age-at-diagnosis (age-at-diagnosis $\geq 50$ years $\mathrm{OR}=0.82$ and 0.80 , respectively; $P=0.04$ and 0.02 ). Thus, variation in the calpain-10 gene may affect risk of type 2 diabetes in Japanese, especially in older individuals.

Keywords Association study · Age-at-diagnosis · Calpain-10 - Genetics · Polymorphism ·

Type 2 diabetes

Y. Tanizawa

Division of Molecular Analysis of Human Disorders,

Department of Bio-Signal Analysis,

Yamaguchi University Graduate School of Medicine,

Ube, Japan

Y. Oka

Division of Molecular Metabolism and Diabetes,

Department of Internal Medicine,

Tohoku University, Sendai, Japan

K. Hara · T. Kadowaki

Department of Metabolic diseases,

Graduate School of Medicine and Faculty of Medicine,

University of Tokyo, Tokyo, Japan

T. Awata

Division of Endocrinology and Diabetes, Department of Medicine, Saitama Medical School, Saitama, Japan

M. Honda

Shiseikai Daini Hospital, Tokyo, Japan

K. Yamashita

Seijin Igaku Medical Clinic, Tokyo, Japan

N. Oda

Department of Internal Medicine,

Fujita Health University School of Medicine,

Aichi, Japan 


\section{Introduction}

The results of association and linkage studies indicate that multiple genes are involved in determining susceptibility to type 2 diabetes in Japanese with each gene making a modest contribution to overall risk (Seino et al. 2001; Mori et al. 2001, 2002; Iwasaki et al. 2003). The gene encoding the cysteine protease calpain-10 (CAPN10) was first found to be associated with risk of type 2 diabetes in studies carried out in Mexican Americans (Horikawa et al. 2000). Two recent metaanalyses and a large association study have confirmed that single nucleotide polymorphisms (SNP)-43 and SNP-44 are associated with a 1.19- and 1.17-fold increased risk, respectively, of type 2 diabetes (Weedon et al. 2003; Song et al. 2004). SNP-43 may be a functional polymorphism affecting transcriptional regulation of the calpain-10 gene (Horikawa et al. 2000; Baier et al. 2000). However, Indel-19 and SNP-63 are just tagging SNPs, and their effect on transcriptional regulation or other functions of calpain-10 are unknown. The effect of the core CAPN10 polymorphisms SNP-43, Indel-19, and SNP-63 on risk of type 2 diabetes in Japanese has been examined in three small studies (Daimon et al. 2002; Horikawa et al. 2003; Shima et al. 2003). The results suggest that variation in CAPN10 is not a major risk factor. However, these studies were not able to quantify the effect of CAPN10 on risk because of the small number of cases and controls in the individual studies. Here, we reexamine the role of the CAPN10 in the development of type 2 diabetes in the Japanese population.

\section{Material and methods}

Subjects

All subjects were Japanese. We studied three groups of cases and controls. The first group (study 1) included 205 unrelated subjects with type 2 diabetes recruited from the outpatient clinic in the Diabetes Center, Tokyo Women's Medical University and 208 unrelated normoglycemic subjects recruited from the Seijin Igaku Medical Clinic of Tokyo Women's Medical University using the following inclusion criteria: age $>60$ years, HbAlc $<5.6 \%$, and no family history of diabetes. The second group (study 2) consisted of 281 unrelated normal glucose-tolerant (by oral glucose tolerance testing) subjects who were recruited at four outpatient clinics: Diabetes Center, Tokyo Women's Medical University $(n=50)$; Third Department of Internal Medicine, Yamaguchi University $(n=121)$; Department of Internal Medicine, University of Tokyo $(n=30)$; and Shiseikai Daini Hospital, Tokyo $(n=80)$. The third group of subjects (study 3) comprised 454 patients with type 2 diabetes and 192 nondiabetic controls who were recruited from Gunma University Hospital and affiliated hospitals and Fujita Health University School of Medicine. The genetic studies were approved by the institutional review board of each participating institution. Informed consent was obtained from all participants.

The pooled analyses included the datasets above as well as the data from three published studies: Daimon et al. 2002, SNP-43; Horikawa et al. 2003, SNP-43, Indel-19 and SNP-63; and Shima et al. 2003, SNP-43, Indel-19, and SNP-63.

Linkage disequilibrium (LD)

We examined the structure of the linkage disequilibrium (LD) in the CAPN10 region using the software package GOLD [graphical overview of linkage disequilibrium (Abecasis and Cookson 2000)] and a common set of 14 SNPs having a minor allele frequency $\geq 0.10$ in diabetic $(n=30)$ and nondiabetic subjects $(n=30)$.

\section{Genotyping}

Genomic DNA was prepared from peripheral blood lymphocytes by standard procedures. We typed three polymorphisms in CAPN10: SNP-43, CAPN10g.4852G > A (rs3792267); insertion/deletion (Indel)-19, CAPN10-g.7920 (32 bp-repeats) (rs3842570); and CAPN10-g.16378C > T (rs5030952) as described previously (Horikawa et al. 2003) or using TaqMan-based assays with custom probes/primers (Applied Biosystems, Foster City, CA, USA). Additional SNPs used for studies of LD in the CAPN10 region were genotyped using TaqMan technology. Previous studies have shown that the three core polymorphisms lead to four common haplotypes described as 111, 112, 121, and 221 (allele 1 or 2 at SNP-43, Indel-19, and SNP-63, respectively). The haplogenotypes were assigned by inspection of the genotypes at SNP-43, Indel-19, and SNP-63.

\section{Statistical analyses}

Polymorphisms were tested for deviation from HardyWeinberg equilibrium, heterogeneity in allele and genotype among studies and differences in allele, genotype, haplotype, and haplogenotype between groups using a chi-squared test. All $P$ values are two sided.

\section{Results}

Haplotype structure across the CAPN10 region

The analysis of LD in the region of CAPN10 revealed a single region of strong LD (Fig. 1).

CAPN10 and SNP-43, and Indel-19 and SNP-63 are contained within this single LD block, which does not 


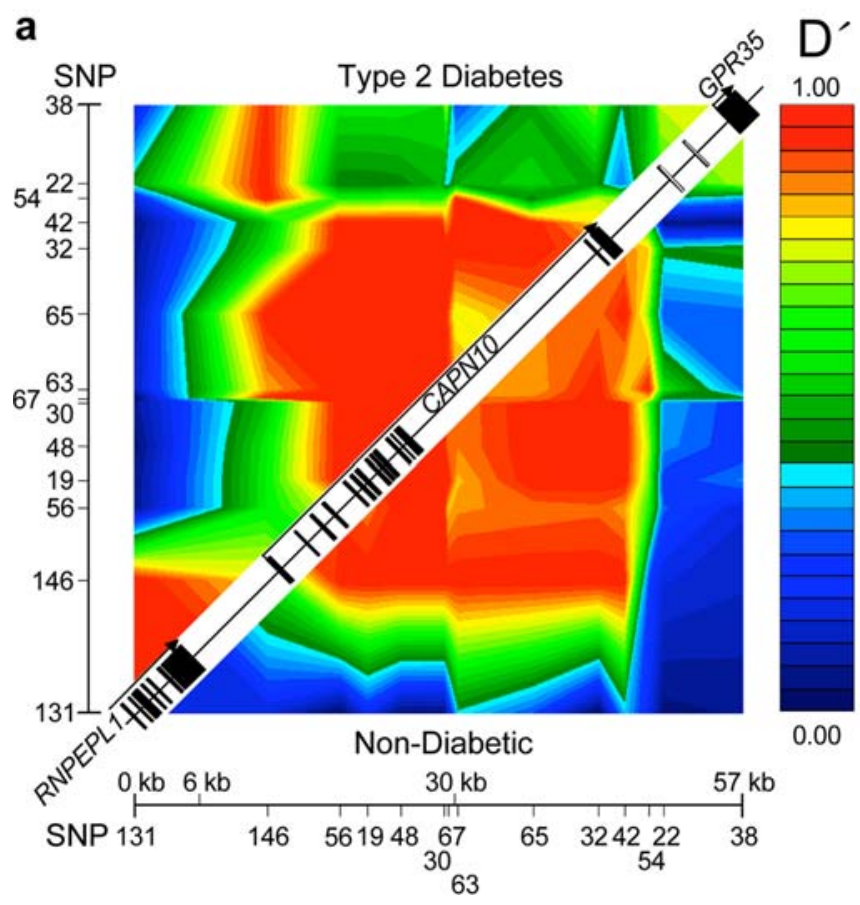

Fig. 1 Linkage disequilibrium (LD) in the CAPN10 region visualized using GOLD. The red and orange regions denote strong LD as defined using D' and $r^{2}$. The exons of CAPN10 and the adjacent genes RNPEPL1 and GPR35 are shown as filled boxes along the diagonal. The two variable number of tandem repeats (VNTRs) between CAPN10 and GPR35 are shown as open boxes. The SNPs used in this analysis are described in Horikawa et al. (2000). SNP-43 was not included in this analysis because the minor allele frequency was $<0.10$ in the Japanese population

include the flanking RNPEPL1 and GPR35 genes. Thus, association of polymorphisms in this block with type 2 diabetes or a type-2-diabetes-related trait in the Japanese population implies that it is a variation in CAPN10 itself and not an adjacent locus that is responsible for the effect. The associated variant may or may not be causal depending on the LD with other variants in the block.

Genetic variation in CAPN10 and type 2 diabetes

We typed SNP-43, Indel-19, and SNP-63 in the three study groups described above (Table 1). There was no significant difference in the frequency of SNP-43 or Indel-19 between cases and controls (Table 2), which is in agreement with previous studies in Japanese (Daimon et al. 2002; Horikawa et al. 2003). However, we observed a significant difference in SNP-63 allele frequency between cases and controls in the subjects from study 1 ( 0.66 and 0.73 , respectively, $P=0.04$ ) but not in the subjects from study 3 (Table 2). In order to gain a better understanding of what role SNP-63 may play in the progression of type 2 diabetes, we examined the effect of SNP-63 genotype on various clinical and metabolic characteristics assessed by a standard 75-g oral glucose tolerance test in a group of 281 normal glucose-tolerant

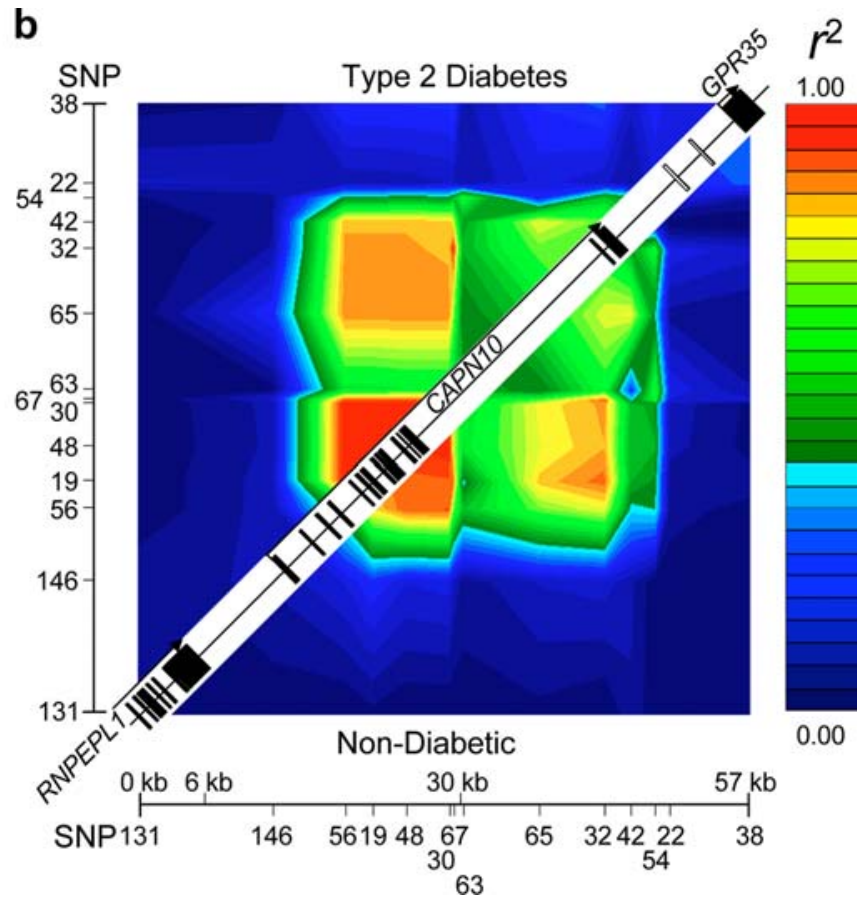

subjects from study 2 (Table 3 ). No significant effects of SNP-63 genotype on phenotype were observed except for area-under-the-curve plasma glucose level from $0 \mathrm{~min}$ to $120 \mathrm{~min}(P=0.03)$.

We then carried out a pooled analysis using data from all known studies carried out in the Japanese population (Daimon et al. 2002; Horikawa et al. 2003; Shima et al. 2003). The 281 nondiabetic subjects from study 2 were excluded from the primary analyses because their mean age-at-study in this group was significantly younger than other the control groups. The pooled study population included 927 patients and 929 controls although Indel-19 and SNP-63 were not typed in all subjects. There was no significant difference in SNP-43, Indel-19, or SNP-63 genotype or allele frequencies between the type 2 diabetic and control groups in the overall analysis (Table 4). There was also no significant difference in SNP-43/Indel-19/SNP-63 haplotype (Table 5) or haplogenotype frequency (Table 6) except for the rare 111/221 combination, which was associated with significantly increased risk of type 2 diabetes $(\mathrm{OR}=3.53, P=0.02)$.

Genetic variation in CAPN10 may modify risk of type 2 diabetes in older patients

Since age is a risk factor for type 2 diabetes, we split the type 2 diabetic group based on median age-atdiagnosis, which was 50 years in the pooled sample, and repeated the comparisons but using only those cases for whom age-at-diagnosis was available: $\mathrm{Pa}$ tients with age-at-diagnosis $<50$ years included 118 patients from study 1, 103 from study 3, and 68 from Horikawa et al. (2003); and patients with age-at-diag- 


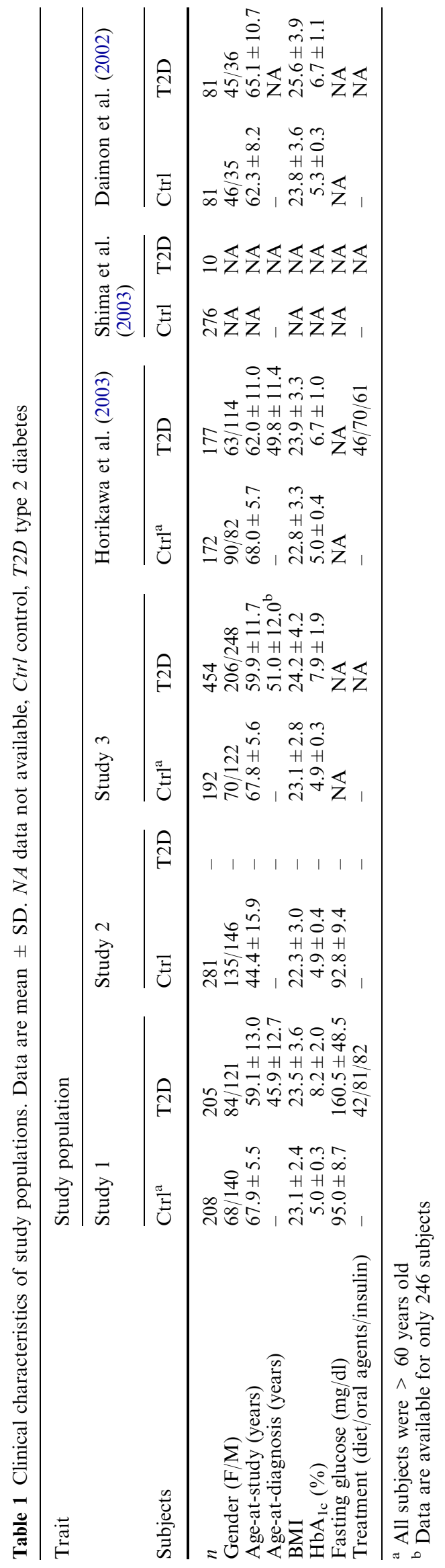

nosis $\geq 50$ years included 87 patients from study 1,143 from study 3, and 85 from Horikawa et al. (2003). There was no significant difference in SNP-43, Indel19, and SNP-63 allele or genotype frequencies between the type 2 diabetic group with age-at-diagnosis $<50$ years and the controls (Table 4 ). The SNP-43 and SNP-63 frequencies were also not different between the type 2 diabetic group with age-at-diagnosis $\geq 50$ years and the controls. However, there was a small but significant difference in Indel-19 allele frequency (Table 4). The 3R allele at Indel-19 (allele 2 in the haplotype) was associated with lower risk of type 2 diabetes $(\mathrm{OR}=0.82, P=0.04)$.

The 121 haplotype was associated with significantly decreased risk $(\mathrm{OR}=0.80, P=0.02)$ of type 2 diabetes in the group of patients with age-at-diagnosis $\geq 50$ years (Table 5). The 111 haplotype had the highest risk $(\mathrm{OR}=1.33, P=0.046)$ in the older group of patients. This effect of the 111 haplotype likely reflects the contribution of SNP-44 to type 2 diabetes risk (Weedon et al. 2003) since $88 \%$ of the 111 haplotypes in Japanese carry the at-risk C-allele at SNP-44. The rare $111 / 221$ haplogenotype was associated with increased risk of type 2 diabetes irrespective of age-at-diagnosis (Table 6). The 121/121 haplogenotype had a protective effect against type 2 diabetes that approached significance in patients with age-at-diagnosis $\geq 50$ years $(\mathrm{OR}=0.76, P=0.06)$. Individuals with haplotypes $111 /$ $111,111 / 112$, and $111 / 221$ had the highest risk of type 2 diabetes $(\mathrm{OR}=1.83,1.25$, and 4.12 , respectively) although the increase in risk was not significant because of the small numbers of individuals studied. If the nondiabetic subjects in study 2 (Table 1) are included in the pooled control group, the results are similar, including the effects of the 121/121 haplogenotype on risk in patients with age-at-diagnosis $\geq 50$ years $(\mathrm{OR}=0.75, P=0.04)$.

\section{Discussion}

The results suggest that genetic variation in CAPN10 may affect risk of type 2 diabetes in the Japanese population, especially in older individuals. Interestingly, the common 121 haplotype appears to be protective in Japanese, suggesting the overall effect of CAPN10 in this population is to reduce the risk of diabetes rather than increase it. It is important to note, though, that the statistical significance of the comparison is marginal $(P=0.01-0.04)$, and none of the comparisons would be significant if corrected for multiple testing. Thus, the results presented here need to be confirmed through studies of a much larger dataset. However, if our results are correct, they suggest an interaction between genetic (CAPN10) and nongenetic (age) factors to modify risk of type 2 diabetes. In this regard, recent studies have shown that calpain-10 is part of a novel apoptotic pathway in insulin-secreting pancreatic beta cells and thus may 
Table 2 Genotype and allele frequencies of CAPN10 polymorphisms in Japanese. The number of subjects of each genotype are indicated All genotypic distributions are in Hardy-Weinberg equilibrium. $N A$ not available, $C t r l$ control, T2D type 2 diabetes

\begin{tabular}{|c|c|c|c|c|c|c|c|c|c|}
\hline Marker & Subjects & Genotype & This study 1 & This study 2 & This study 3 & $\begin{array}{l}\text { Horikawa } \\
\text { et al. (2003) }\end{array}$ & $\begin{array}{l}\text { Shima } \\
\text { et al. (2003) }\end{array}$ & $\begin{array}{l}\text { Daimon } \\
\text { et al. } \\
(2002)\end{array}$ & $\begin{array}{l}P \text { for } \\
\text { heterogeneity }\end{array}$ \\
\hline \multirow[t]{10}{*}{ SNP-43 } & \multirow[t]{5}{*}{ Ctrl } & $\mathrm{G} / \mathrm{G}$ & 188 & 251 & 165 & 154 & 252 & 76 & \\
\hline & & $\mathrm{G} / \mathrm{A}$ & 20 & 29 & 24 & 18 & 24 & 5 & \\
\hline & & $\mathrm{A} / \mathrm{A}$ & 0 & 1 & 0 & 0 & 0 & 0 & 0.75 \\
\hline & & \multirow[t]{2}{*}{ Allele frequency } & G: 0.95 & G: 0.94 & G: 0.94 & G: 0.95 & G: 0.96 & G: 0.97 & \\
\hline & & & A: 0.05 & A: 0.06 & A: 0.06 & A: 0.05 & A: 0.04 & A: 0.03 & 0.62 \\
\hline & \multirow[t]{5}{*}{$\mathrm{T} 2 \mathrm{D}$} & $\mathrm{G} / \mathrm{G}$ & 184 & NA & 389 & 158 & 8 & 76 & \\
\hline & & $\mathrm{G} / \mathrm{A}$ & 21 & NA & 57 & 19 & 2 & 5 & \\
\hline & & $\mathrm{A} / \mathrm{A}$ & 0 & NA & 1 & 0 & 0 & 0 & 0.75 \\
\hline & & Allele frequency & G: 0.95 & NA & G: 0.93 & G: 0.95 & G: 0.90 & G: 0.97 & \\
\hline & & & A: 0.05 & & A: 0.07 & A: 0.05 & A: 0.10 & A: 0.03 & 0.37 \\
\hline \multirow[t]{10}{*}{ Indel-19a } & \multirow[t]{5}{*}{$\mathrm{Ctrl}$} & $2 \mathrm{R} / 2 \mathrm{R}$ & 27 & 42 & 35 & 23 & 42 & NA & \\
\hline & & $2 \mathrm{R} / 3 \mathrm{R}$ & 99 & 126 & 78 & 78 & 126 & NA & \\
\hline & & $3 \mathrm{R} / 3 \mathrm{R}$ & 82 & 113 & 73 & 71 & 108 & NA & 0.90 \\
\hline & & \multirow[t]{2}{*}{ Allele frequency } & 2R: 0.37 & 2R: 0.37 & 2R: 0.40 & 2R: 0.36 & 2R: 0.38 & \multirow[t]{2}{*}{ NA } & \\
\hline & & & 3R: 0.63 & 3R: 0.63 & 3R: 0.60 & 3R: 0.64 & 3R: 0.62 & & 0.86 \\
\hline & \multirow[t]{5}{*}{$\mathrm{T} 2 \mathrm{D}$} & $2 \mathrm{R} / 2 \mathrm{R}$ & 32 & NA & 63 & 28 & 1 & NA & \\
\hline & & $2 \mathrm{R} / 3 \mathrm{R}$ & 104 & NA & 209 & 82 & 3 & NA & \\
\hline & & $3 \mathrm{R} / 3 \mathrm{R}$ & 69 & NA & 176 & 67 & 6 & NA & 0.62 \\
\hline & & \multirow{2}{*}{ Allele frequency } & 2R: 0.41 & NA & 2R: 0.37 & 2R: 0.39 & 2R: 0.25 & \multirow[t]{2}{*}{ NA } & \\
\hline & & & 3R: 0.59 & & 3R: 0.63 & 3R: 0.61 & 3R: 0.75 & & 0.34 \\
\hline \multirow[t]{10}{*}{ SNP-63 } & \multirow[t]{5}{*}{ Ctrl } & $\mathrm{C} / \mathrm{C}$ & 111 & 151 & 99 & 90 & 151 & NA & \\
\hline & & $\mathrm{C} / \mathrm{T}$ & 81 & 106 & 65 & 70 & 103 & NA & \\
\hline & & $\mathrm{T} / \mathrm{T}$ & 16 & 24 & 18 & 12 & 22 & NA & 0.99 \\
\hline & & \multirow[t]{2}{*}{ Allele frequency } & C: 0.73 & C: 0.73 & C: 0.72 & C: 0.73 & C: 0.73 & \multirow[t]{2}{*}{ NA } & \\
\hline & & & $\mathrm{T}: 0.27$ & $\mathrm{~T}: 0.27$ & $\mathrm{~T}: 0.28$ & $\mathrm{~T}: 0.27$ & $\mathrm{~T}: 0.27$ & & 0.99 \\
\hline & \multirow[t]{5}{*}{$\mathrm{T} 2 \mathrm{D}$} & $\mathrm{C} / \mathrm{C}$ & 90 & NA & 255 & 93 & 6 & NA & \\
\hline & & $\mathrm{C} / \mathrm{T}$ & 92 & NA & 165 & 74 & 3 & NA & \\
\hline & & $\mathrm{T} / \mathrm{T}$ & 23 & NA & 30 & 10 & 1 & NA & 0.09 \\
\hline & & \multirow[t]{2}{*}{ Allele frequency } & $C: 0.66$ & NA & $C: 0.75$ & $C: 0.73$ & $C: 0.75$ & \multirow[t]{2}{*}{ NA } & \\
\hline & & & $\mathrm{T}: 0.34$ & & $\mathrm{~T}: 0.25$ & $\mathrm{~T}: 0.27$ & $\mathrm{~T}: 0.25$ & & 0.03 \\
\hline
\end{tabular}

${ }^{a}$ Indel-19 is a diallelic insertion/deletion polymorphism with alleles of two repeats (2R) or three repeats (3R) of a 32-bp sequence

Table 3 Clinical and metabolic characteristics of normal glucose tolerant subjects (study 2) by SNP-63 genotype. Data are mean \pm SD. Subjects underwent a standard 75 -g oral glucose tolerance test with glucose and insulin determined at $0^{\prime}, 30^{\prime}, 60^{\prime}$, and $120^{\prime}$. The number of individuals in each group for determination of insulinogenic index and HOMA are noted in parentheses. BMI body mass index, $A U C$ area under the curve

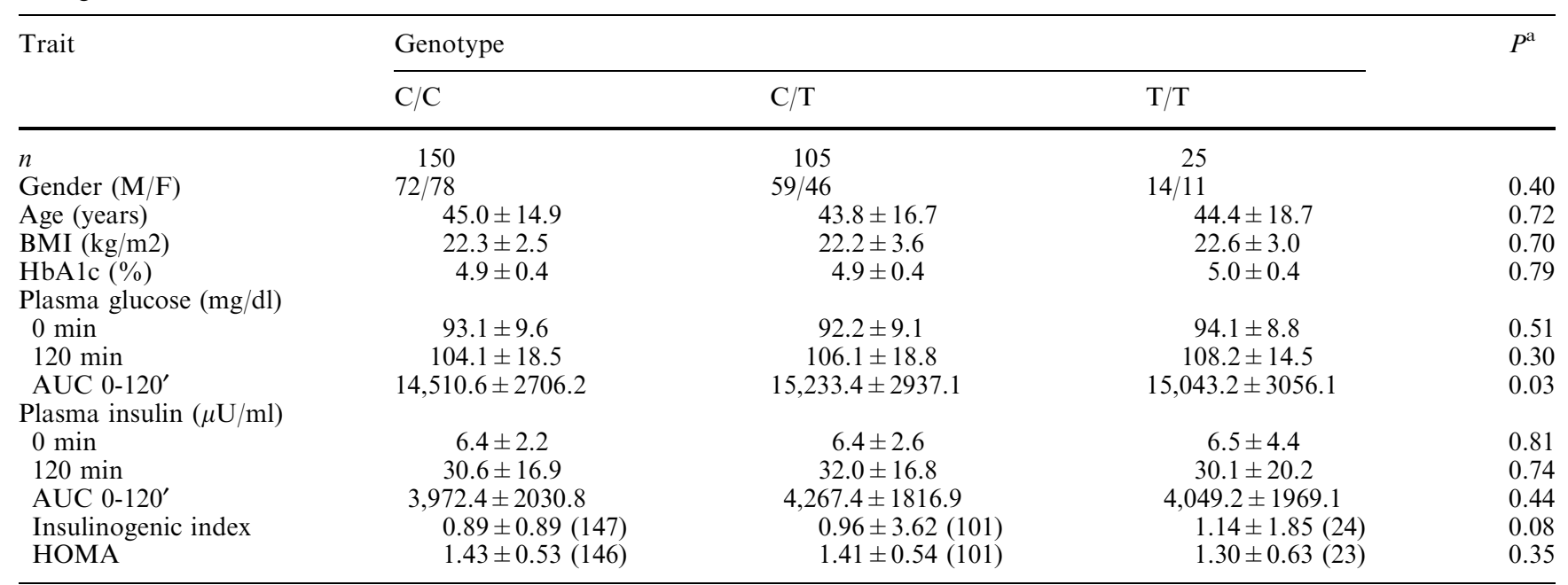

${ }^{\text {a }} P$ value by ANCOVA with institution, gender, and genotype as independent factors and age and BMI as covariates

affect the response of the beta cell to aging or its ability to compensate in response to an increasing demand for insulin (Johnson et al. 2004).
The observation that individuals homozygous for the 121 haplotype may be at increased risk of type 2 diabetes in some European populations (Orho- 
Table 4 SNP-43, Indel-19, and SNP-63 and type 2 diabetes in Japanese - a pooled analysis. The number of subjects of each genotype are indicated. All genotypic distributions are in HardyWeinberg equilibrium. The cases were divided into two groups based on the median age-at-diagnosis in the pooled sample -50 years. Note that age-at-diagnosis was not available for all subjects

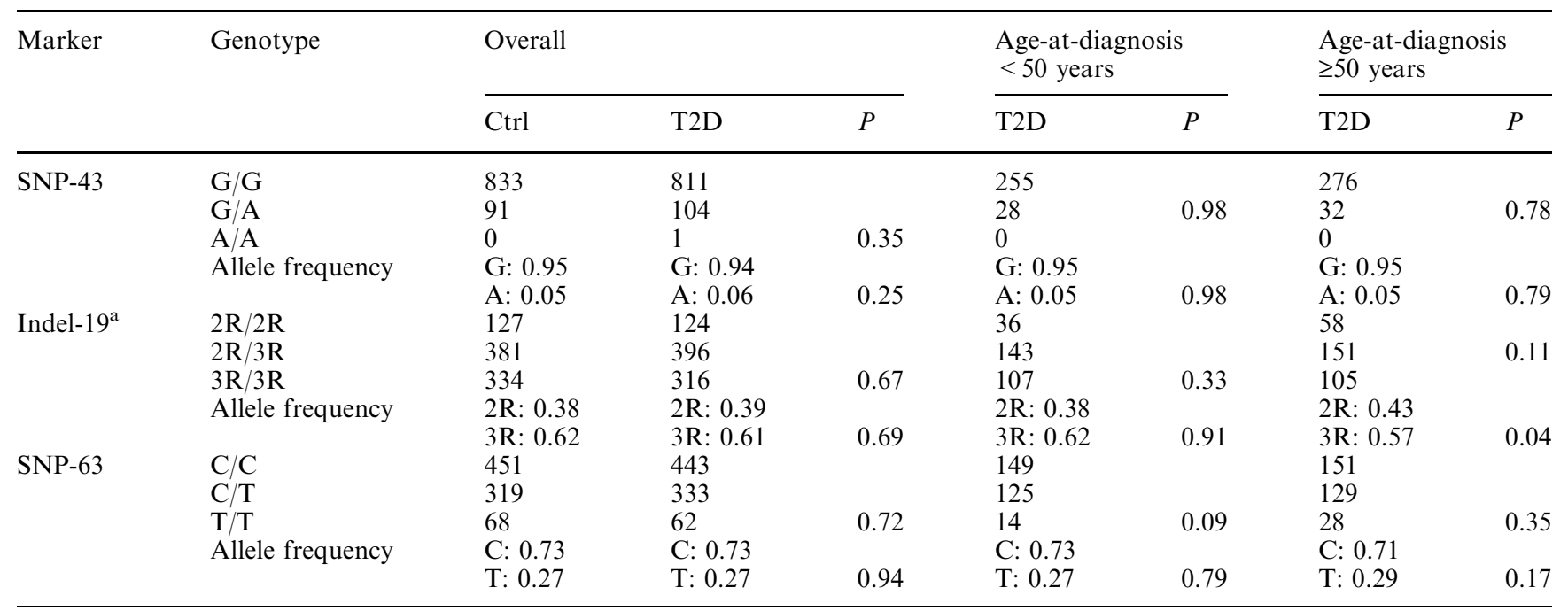

${ }^{\mathrm{a}}$ Indel-19: 2R, 2 repeats of 32-bp sequence; 3R, 3 repeats

Table 5 CAPN10 haplotype frequency and risk of type 2 diabetes in Japanese - a pooled analysis. The haplotypes are those defined by SNP-43, Indel-19, and SNP-63, and the specific alleles are: SNP43, allele 1, G and allele 2, A; Indel-19, allele 1, 2 repeats of 32-bp sequence, and allele 2, 3 repeats; and SNP-63, allele 1, C, and allele
$2, \mathrm{~T}$. The cases were divided into two groups based on the median age-at-diagnosis in the pooled sample - 50 years. Note that age-atdiagnosis was not available for all subjects. Ctrl control, T2D type 2 diabetes

\begin{tabular}{|c|c|c|c|c|c|c|c|c|c|c|}
\hline \multirow[t]{2}{*}{ Haplotype } & \multicolumn{4}{|l|}{ Overall } & \multicolumn{3}{|c|}{ Age-at-diagnosis $<50$ years } & \multicolumn{3}{|c|}{ Age-at-diagnosis $\geq 50$ years } \\
\hline & $\begin{array}{l}\text { Ctrl } \\
(n=825)\end{array}$ & $\begin{array}{l}\text { T2D } \\
(n=827)\end{array}$ & $\begin{array}{l}\text { OR } \\
(95 \% \mathrm{CI})^{\mathrm{a}}\end{array}$ & $P$ & $\begin{array}{l}\text { T2D } \\
(n=277)\end{array}$ & $\begin{array}{l}\text { OR } \\
(95 \% \mathrm{CI})^{\mathrm{a}}\end{array}$ & $P$ & $\begin{array}{l}\text { T2D } \\
(n=305)\end{array}$ & $\begin{array}{l}\text { OR } \\
(95 \% \mathrm{CI})^{\mathrm{a}}\end{array}$ & $P$ \\
\hline 111 & 0.106 & 0.113 & $1.07(0.86-1.34)$ & 0.52 & 0.117 & $1.12(0.83-1.52)$ & 0.46 & 0.136 & $1.33(1.00-1.75)$ & 0.05 \\
\hline 121 & 0.572 & 0.553 & $0.93(0.81-1.07)$ & 0.29 & 0.567 & $0.98(0.81-1.19)$ & 0.85 & 0.515 & $0.80(0.66-0.96)$ & 0.02 \\
\hline 112 & 0.270 & 0.274 & $1.02(0.88-1.19)$ & 0.79 & 0.265 & $0.98(0.78-1.21)$ & 0.82 & 0.297 & $1.14(0.93-1.40)$ & 0.21 \\
\hline 221 & 0.052 & 0.059 & $1.15(0.85-1.54)$ & 0.37 & 0.051 & $0.97(0.62-1.50)$ & 0.88 & 0.052 & $1.01(0.66-1.53)$ & 0.97 \\
\hline
\end{tabular}

${ }^{\mathrm{a}}$ The OR and $95 \%$ CI of each haplotype relative to other haplotypes as a group are shown

Table 6 CAPN10 haplogenotype and risk of type 2 diabetes in Japanese - a pooled analysis. The haplotypes are those defined by SNP-43, Indel-19, and SNP-63, and the specific alleles are indicated in the legend to Table 5. The number of individuals with each haplogenotype is indicated

\begin{tabular}{|c|c|c|c|c|c|c|c|c|c|c|}
\hline \multirow[t]{2}{*}{ Haplogenotype } & \multicolumn{4}{|c|}{ Overall } & \multicolumn{3}{|c|}{ Age-at-diagnosis $<50$ years } & \multicolumn{3}{|c|}{ Age-at-diagnosis $\geq 50$ years } \\
\hline & Ctrl & $\mathrm{T} 2 \mathrm{D}$ & OR $(95 \% \mathrm{CI})^{\mathrm{a}}$ & $P$ & $\mathrm{~T} 2 \mathrm{D}$ & OR $(95 \% \mathrm{CI})^{\mathrm{a}}$ & $P$ & $\mathrm{~T} 2 \mathrm{D}$ & OR $(95 \% \mathrm{CI})^{\mathrm{a}}$ & $P$ \\
\hline $111 / 111$ & 15 & 18 & $1.20(0.60-2.40)$ & 0.60 & 5 & $0.99(0.36-2.76)$ & 0.99 & 10 & $1.83(0.82-4.07)$ & 0.14 \\
\hline $111 / 121$ & 97 & 93 & $0.95(0.70-1.29)$ & 0.74 & 31 & $0.95(0.62-1.45)$ & 0.80 & 37 & $1.04(0.69-1.55)$ & 0.86 \\
\hline $111 / 112$ & 44 & 44 & $1.00(0.65-1.53)$ & 0.99 & 18 & $1.23(0.70-2.17)$ & 0.47 & 20 & $1.25(0.72-2.15)$ & 0.43 \\
\hline $111 / 221$ & 4 & 14 & $3.53(1.24-10.1)$ & 0.02 & 6 & $4.54(1.42-14.5)$ & 0.01 & 6 & $4.12(1.27-13.3)$ & 0.02 \\
\hline $112 / 112$ & 66 & 62 & $0.93(0.65-1.34)$ & 0.70 & 13 & $0.57(0.31-1.04)$ & 0.06 & 27 & $1.12(0.70-1.78)$ & 0.64 \\
\hline $112 / 121$ & 247 & 254 & $1.04(0.84-1.28)$ & 0.73 & 90 & $1.13(0.84-1.51)$ & 0.43 & 97 & $1.09(0.82-1.45)$ & 0.55 \\
\hline $112 / 221$ & 23 & 32 & $1.40(0.82-2.41)$ & 0.22 & 13 & $1.72(0.86-3.41)$ & 0.12 & 10 & $1.18(0.56-2.51)$ & 0.66 \\
\hline $121 / 121$ & 270 & 259 & $0.94(0.76-1.15)$ & 0.54 & 92 & $1.02(0.77-1.37)$ & 0.88 & 82 & $0.76(0.56-1.01)$ & 0.06 \\
\hline $121 / 221$ & 59 & 50 & $0.84(0.57-1.23)$ & 0.37 & 9 & $0.44(0.22-0.87)$ & 0.02 & 16 & $0.72(0.41-1.27)$ & 0.25 \\
\hline $221 / 221$ & 0 & 1 & - & - & 0 & & & 0 & & \\
\hline
\end{tabular}

a The OR and $95 \%$ CI of each haplogenotype relative to the other haplotype combinations as a group are shown

Melander et al. 2002; Malecki et al. 2002) but at decreased risk in older Japanese raises the possibility that additional genetic variation may distinguish high- and low-risk subtypes of the 121 haplotype. Transpopulation mapping may be a useful strategy for identifying this variation. 
Acknowledgements The authors thank Ms. A. Nogami, Ms. M. Y. Sagisaka, and Mr. M. Ikeda for their skillful technical assistance. This study was supported by Grants-in-Aid for Scientific Research C (10671084, 10470234) and for Scientific Research on Priority Areas Medical Genome Science from the Japan Ministry of Science, Education, Sports, Culture and Technology (12204102, 13204082, 14013059, 15012250), Novo Nordisk Foundation, the Naito Foundation (to N.I.) and Grants-in-Aid for Scientific Research B (13470223, 13557091) (to Y.H.), and U.S. Public Health Service (Grants DK-20595, -47486 and -55889 ). G.I.B. is an Investigator of the Howard Hughes Medical Institute.

\section{References}

Abecasis GR, Cookson WO (2000) GOLD-graphical overview of linkage disequilibrium. Bioinformatics 16:182-183

Baier LJ, Permana PA, Yang X, Pratley RE, Hanson RL, Shen GQ, Mott D, Knowler WC, Cox NJ, Horikawa Y, Oda N, Bell GI, Bogardus C (2000) A 1-10 gene polymorphism is associated with reduced muscle mRNA levels and insulin resistance. J Clin Invest 106:R69-R73

Daimon M, Oizumi T, Saitoh T, Kameda W, Yamaguchi H, Ohnuma H, Igarashi M, Manaka H, Kato T (2002) Calpain-10 gene polymorphisms are related, not to type 2 diabetes, but to increased serum cholesterol in Japanese. Diabetes Res Clin Pract 56:147-152

Horikawa Y, Oda N, Cox NJ, Li X, Orho-Melander M, Hara M, Hinokio Y, Lindner TH, Mashima H, Schwarz PE, del BosquePlata L, Oda Y, Yoshiuchi I, Colilla S, Polonsky KS, Wei S, Concannon P, Iwasaki N, Schulze J, Baier LJ, Bogardus C, Groop L, Boerwinkle E, Hanis CL, Bell GI (2000) Genetic variation in the gene encoding calpain-10 is associated with type 2 diabetes mellitus. Nat Genet 26:163-175

Horikawa Y, Oda N, Yu L, Imamura S, Fujiwara K, Makino M, Seino Y, Itoh M, Takeda J (2003) Genetic variations in calpain10 gene are not a major factor in the occurrence of type 2 diabetes in Japanese. J Clin Endocrinol Metab 88:244-247

Iwasaki N, Cox NJ, Wang YQ, Schwarz PE, Bell GI, Honda M, Imura M, Ogata M, Saito M, Kamatani N, Iwamoto Y (2003) Mapping genes influencing type 2 diabetes risk and BMI in Japanese subjects. Diabetes 52:209-213

Johnson JD, Han Z, Otani K, Ye H, Zhang H, Wu H, Horikawa Y, Misler S, Bell GI, Polonsky KS (2004) RyR2 and calpain-10 delineate a novel apoptosis pathway in pancreatic islets. J Biol Chem 279:24794-24802
Malecki MT, Moczulski DK, Klupa T, Wanic K, Cyganek K, Frey J, Sieradzki J (2002) Homozygous combination of calpain 10 gene haplotypes is associated with type 2 diabetes mellitus in a Polish population. Eur J Endocrinol 146:695699

Mori H, Ikegami H, Kawaguchi Y, Seino S, Yokoi N, Takeda J, Inoue I, Seino Y, Yasuda K, Hanafusa T, Yamagata K, Awata T, Kadowaki T, Hara K, Yamada N, Gotoda T, Iwasaki N, Iwamoto Y, Sanke T, Nanjo K, Oka Y, Matsutani A, Maeda E, Kasuga M (2001) The Pro12 $\rightarrow$ Ala substitution in PPAR- $\gamma$ is associated with resistance to development of diabetes in the general population: possible involvement in impairment of insulin secretion in individuals with type 2 diabetes. Diabetes 50:891-894

Mori Y, Otabe S, Dina C, Yasuda K, Populaire C, Lecoeur C, Vatin V, Durand E, Hara K, Okada T, Tobe K, Boutin P, Kadowaki T, Froguel P (2002) Genome-wide search for type 2 diabetes in Japanese affected sib-pairs confirms susceptibility genes on 3q, 15q, and 20q and identifies two new candidate Loci on $7 \mathrm{p}$ and $11 \mathrm{p}$. Diabetes 51:1247-1255

Orho-Melander M, Klannemark M, Svensson MK, Ridderstrale M, Lindgren CM, Groop L (2002) Variants in the calpain-10 gene predispose to insulin resistance and elevated free fatty acid levels. Diabetes 51:2658-2664

Seino S on behalf of the Study Group of Comprehensive Analysis of Genetic Factors in Diabetes Mellitus (2001) S20G mutation of the amylin gene is associated with Type II diabetes in Japanese. Diabetologia 44:906-909

Shima Y, Nakanishi K, Odawara M, Kobayashi T, Ohta H (2003) Association of the SNP-19 genotype 22 in the calpain-10 gene with elevated body mass index and hemoglobin Alc levels in Japanese. Clin Chim Acta 336:89-96

Song Y, Niu T, Manson JE, Kwiatkowski DJ, Liu S (2004) Are variants in the CAPN10 gene related to risk of type 2 diabetes? A quantitative assessment of population and family-based association studies. Am J Hum Genet 74:208-222

Weedon MN, Schwarz PE, Horikawa Y, Iwasaki N, Illig T, Holle R, Rathmann W, Selisko T, Schulze J, Owen KR, Evans J, Del Bosque-Plata L, Hitman G, Walker M, Levy JC, Sampson M, Bell GI, McCarthy MI, Hattersley AT, Frayling TM (2003) Meta-analysis and a large association study confirm a role for calpain-10 variation in type 2 diabetes susceptibility. Am J Hum Genet 73:1208-1212 